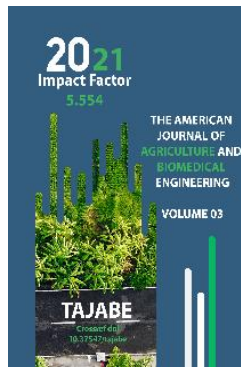

Journal Website: https://theamericanjou rnals.com/index.php/ta jabe

Copyright: Original content from this work may be used under the terms of the creative commons attributes 4.0 licence.

\section{Application Of Water-Saving Technologies In Gardening Uzbekistan}

\author{
Sarimsakov Maksudkhon Musinovich \\ Candidate Of Agricultural Sciences, Associate Professor Of The Department Of The Fergana \\ Polytechnic Institute, Fergana, Uzbekistan \\ Kimsanov Ibrahim Khaitmuratovich \\ Candidate Of Agricultural Sciences, Associate Professor Of The Department Of The Fergana \\ Polytechnic Institute, Fergana, Uzbekistan \\ Umarova Zulaykho Tulkunovna \\ Candidate Of Agricultural Sciences, Associate Professor Of The Department Of The Tashkent \\ State Agrarian University, Tashkent, Uzbekistan
}

\title{
ABSTRACT
}

As a result, existing water shortages in Uzbekistan eliminate the negative consequences arising, effective and rational use of water and land resources, the use of water-saving technologies in irrigation of crops helps to save water and other resources up to 35-50\%. The development of horticulture and viticulture increases the efficiency of land use in mountain and foothill areas, at the same time satisfies the need for fruits and grapes of the local population, and also serves as the main foundation of the domestic market with cheap enrichment and quality products.

\section{KEYWORDS}

Intensive garden, apple tree, irrigation method, soil moisture, the efficiency of irrigated lands, watersaving technologies, plastic film, soil salinity, groundwater depth, water-saving, apple yield.

\section{INTRODUCTION}

Today in many countries of the world, as well as in the Central Asian region, especially in Uzbekistan, the need for water resources is growing, and the problem of water scarcity is growing from year to year. Until 2000, low water was observed once every 6-8 years, but in recent years this process has been repeated every 3-4 years [2,37].

What makes water scarcity such a global, regional problem? Looking back, by 1960 the area of irrigated land in the entire Central Asian region was 5 million hectares. However, it was 
during this period that the "Program" was developed to transform Central Asia into a single cotton plantation. Until 1960, $40 \mathrm{~km} 3$ of water was used per year to irrigate existing crops, and by the 1980s, the volume of water consumed reached $132 \mathrm{~km} 3$. Until 1960, the volume of water in the Aral Sea was 1,040 km3, by 1990 the Aral Sea was divided into two, the Big Aral and the Small Aral, and by 2005 the total volume of water in these seas was only $112.3 \mathrm{~km} 3$. Over the past 45 years, the Aral Sea has decreased by almost 9.3 times. In such a tragic situation, it is the misuse of protected lands and the cultivation of water-intensive crops $[2,7]$.

The reforms carried out by our government to overcome the existing problems are a key factor in the improvement and further development of each sector.

The decree of the President of the Republic of Uzbekistan dated December 29, 2015 "On measures for further reform and development of agriculture in 2016-2020" laid the foundation for bringing the industry to a new level.

The decree provides for the sowing of 170 thousand hectares of cotton and 50 thousand hectares of grain, a total of 220 thousand hectares of irrigated land by 2020, sowing potatoes, vegetables, melons, oilseeds and food crops, as well as the creation of new intensive orchards. It is planned to reduce the acreage under such crops due to low soil fertility, poor reclamation and water supply, and in recent years, the cotton harvest does not exceed 10-15 centners per hectare $[1,7]$.

The government has carried out large-scale work on the efficient and targeted use of the country's land and water resources, developed and implemented several state programs.

The only example of the implementation of state programs is the release of the Parkent, Bostanlyk, Yangiyul, Zangiotinsky, Samarkand, Dzhambaysky, Asaka districts from the obligation to grow cotton and specialize in growing fruits, vegetables and grapes.

Now the attitude of farmers towards the land has changed. Fundamental changes have taken place in agricultural production, that is, a new class of owners has appeared - farms. The current problem of water scarcity in the country's agriculture, namely in the field of agriculture, causes various inconveniences for the cultivation of agricultural products. However, the transfer of arable land to its owners makes it possible to consistently solve such problems. The most important thing is that all landowners understand that the most important and relevant today is to meet the needs of the country's population in food products, as well as in industrial production and our domestic markets with high-quality and affordable products $[2,4,5,6]$.

$90 \%$ of Uzbekistan's available water resources are used for irrigation. The main part of this amount (80-83\%) falls on the growing season. During the period of the novelization, water is used for irrigation of winter crops, wet harvesting and pre-sowing irrigation, flushing of saline soils on saline soils. The volume of water consumption in irrigated agriculture depends on the natural and economic conditions, the technical condition of the irrigation systems, as well as on the method and technique of irrigation used. 
On average, $80 \%$ of the water used in the country comes from neighbouring countries. The pumps supply water for about 70 per cent of the irrigated land.

More than 836 billion soums are allocated annually from the budget for the water management complex (operating costs), of which 551.7 billion soums. 123.7 billion soums of wages, 160.6 billion soums of mandatory payments, etc.

This led to a $50 \%$ reduction in the area under low-water crops in our country, and an expansion of the area under low-water crops. Therefore, in recent years, much attention has been paid to the selection and implementation of water-saving technologies for growing crops, as well as meeting the population's demand for food and agricultural products, enriching farmers' markets with cheap and high-quality agricultural products. Several state programs have been developed for intensive and semi-intensive orchards and vineyards $[3,4,5,6]$.

\section{MATERIALS AND METHODS}

Based on current programs with the development of the scientific and practical basis of resource-saving technologies for the cultivation of gardens and vineyards, scientific research is carried out on the growing territory of the Syrdarya region of Syrdarya [4].

The field experiment was carried out in the apple orchards of Syrdarya Oltin Tola Bogi LLC. The experimental field is located in the Shurozak basin of Mirzachul, old-fashioned and close to the groundwater level (1.5-2.0 m). The Shurozak basin occupies the southwestern part of the second terrace of the Syrdarya. The bulk density of the soil is $1.25 \mathrm{~g} / \mathrm{cm} 3$ in the $0-30$ $\mathrm{cm}$ layer at the beginning of the application period and $1.32 \mathrm{~g} / \mathrm{cm} 3$ in the $30-50 \mathrm{~cm}$ layer.

The Shurozak basin borders on the neighbouring Tashkent region of the Syrdarya region and the Republic of Kazakhstan and includes four districts: Gulistan, Mirzaabad, Saykhunabad and Syrdarya. Saykhunabad district borders in the south with Boevutsky district, and in the south-west - with Ak-Altyn district. In the west, it borders on the neighbouring Republic of Kazakhstan. In the northeast, it borders the Tashkent region and the Syrdarya river.

The climate of the region is sharply continental, hot summer, which leads to the evaporation of groundwater, salinization of soils, especially the lands of the Mirzaabad region are very saline, the overall productivity of the region is low, the temperature in summer is hotter than in the Tashkent region, slightly lower in winter, moderate precipitation is sometimes possible in spring. snowfall. The land plots of the district are provided with nutrients. The soils of the Saykhunabad region are divided into the following groups:

1) Irrigated hungry grey soils; coarsegrained sandy loam - coarse-grained sandy loam and coarse-grained loamy sandy loam soil in proluvial deposits;

2) Meadow irrigated alluvial soils; unsalted and slightly salted, sandy loam and clayey, located in sandy loam and pebble deposits of the second terrace of the Syrdarya river.

3) The newly irrigated earthy meadow is located in alluvial deposits of clay- 
The American Journal of Agriculture and Boimedical Engineering (ISSN - 2689-1018)

sandy soil with a thin layer of sand and gravel.

4) alluvial meadow soils; It is sandy loam and loamy, with clay and sandy soils, located in pebble sandy loamy layered alluvial deposits of the first inclined terrace of the Syr Darya River. Irrigated and re-irrigated meadows and alluvial soils constitute the main fund of the district's soil cover. They are developed in alluvial deposits in the form of medium to heavy sandy soils and clays.

The Shurozak-Syrdarya irrigation system serves the irrigated lands of the region.

The soils of the experimental fields consist of medium and slightly saline, in terms of the texture of medium and light sandy meadow grey and waterlogged meadow soils (Fig.1-3).

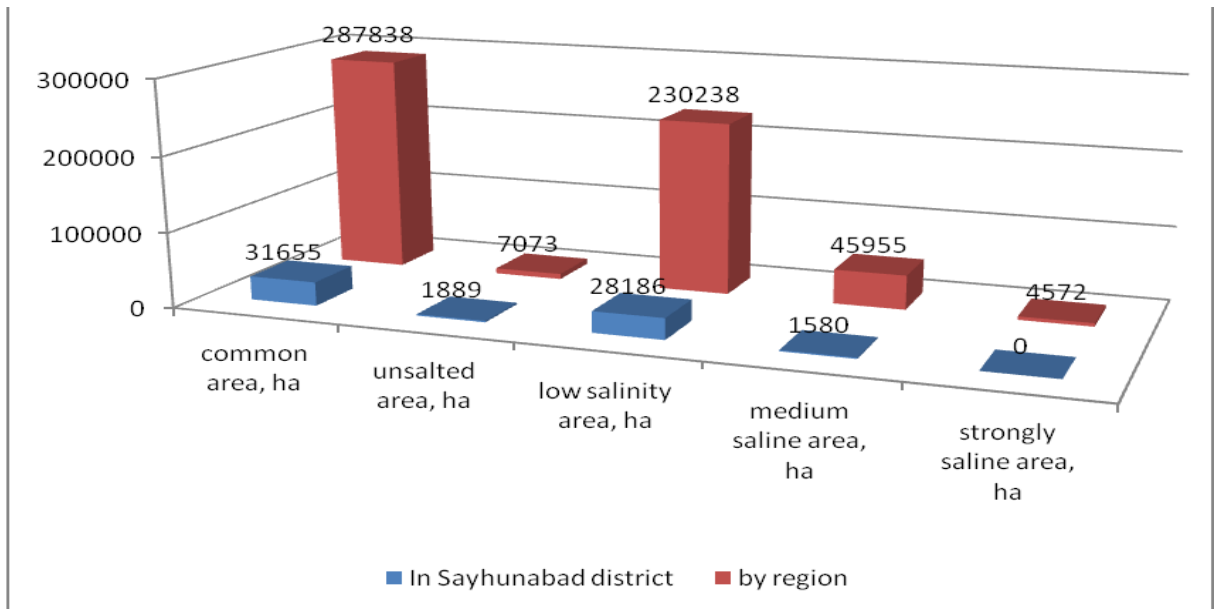

Figure 1. Categories of salinity of irrigated lands of Sayhunabad district.

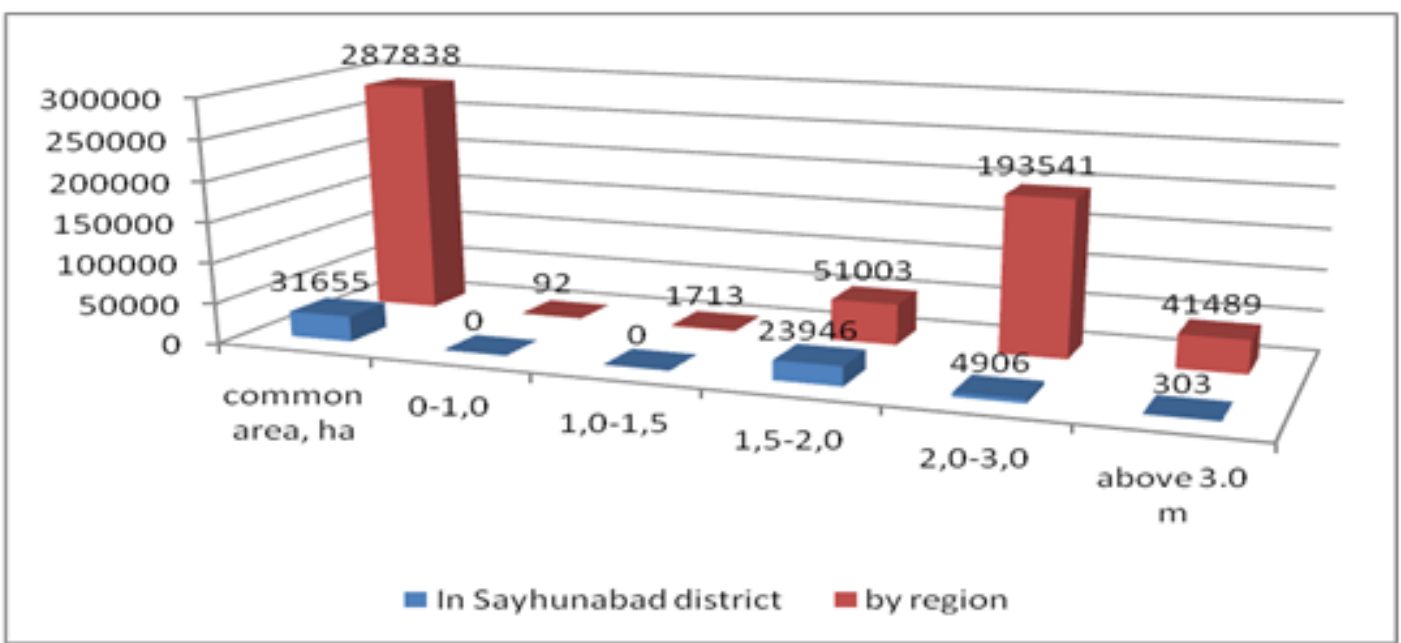

Figure 2. Depth of groundwater level in irrigated areas of Sayhunabad district. 
The American Journal of Agriculture and Boimedical Engineering (ISSN - 2689-1018)

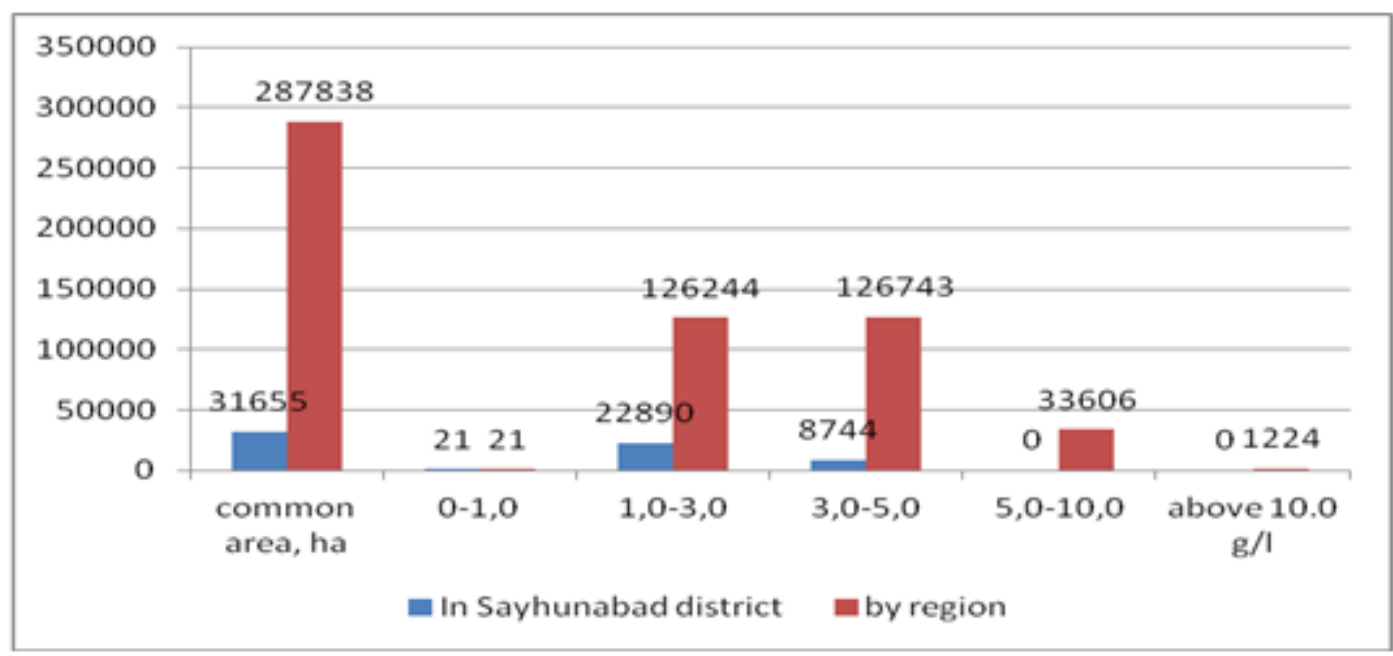

Figure 3. Groundwater salinity in irrigated areas of Sayhunabad district.

From the graphical data, it can be seen that the main part of the irrigated lands of the Saykhunabad region has low salinity, the level of groundwater is $1.5-2.0 \mathrm{~m}$, and their salinity is $1.0-3.0 \mathrm{~g} / \mathrm{l}$.

The soils of the studied region are moderately saline, the groundwater level is $\mathbf{1} \cdot \mathbf{5 - 2 . 0} \mathrm{m}$, and their salinity is 3.0-5.0 g/l.

The main task of our specialists and scientists is to use modern advanced agricultural technologies in areas with low yields, reclamation conditions and complex water supply, to obtain high and high-quality yields, and most importantly, to improve the reclamation of irrigated lands. and development of measures for the efficient use of water resources.

There are more than 700,000 hectares of mountainous and foothill territories in the country, which play an important role in the development of horticulture and viticulture, providing the needs of the population and domestic markets with fruits and grapes. The creation of orchards and vineyards in these areas is a key factor in the efficient use of land resources. In such areas, the use of modern water-saving irrigation technologies allows achieving comprehensive economic efficiency.

In our experiments, we used the method of watering gardens by building up the edges of plastic wrap. This method prevented the useless infiltration of water into the soil and provided a $15-20 \%$ savings in irrigation water.

\section{Hydraulic calculation of irrigation by laying film on irrigation furrows.}

When watering orchards and vineyards, the hydraulic calculation of the film edge coverage is very important. The water flow rate, pressure water depth, cross-sectional area and water velocity in the foil embankment must be accurately calculated in accordance with the water flow rate at each edge.

The movement of the flow of water in the edges of the film lined corresponds to the smooth movement of the flow at a distance from one tree seedling to another. The flow 
rate of water in a direct flow is determined by the following formula.

$Q=\omega \cdot C \sqrt{R \cdot i}, \quad\left(\mu^{3} / c, \pi / c\right)$

Here:

$\omega=(b+m h) h$ the trapezoidal free crosssectional area of the riverbed, $\mathrm{m}^{2} ;$ (1)

b, $m$ - width and slope coefficient of the channel bottom

C- coefficient of Chézy $\mathrm{m}^{0,5} / \mathrm{c}$;

$R=\frac{\omega}{\chi}$

hydraulic radius, $\mathrm{m}$ (2)

$\chi=b+2 h \sqrt{m^{2}+1}$

wetted perimeter (3)

$i$-the slope of the channel bottom.

The Shezy coefficient can be determined using Manning's formula:
$C=\frac{1}{n} R^{\frac{1}{6}}$

It should be noted that $\mathrm{n}$ is the roughness coefficient of the flow channel in the Chezy coefficient, which is determined experimentally.

The water consumption at the foil fence is determined in the following way proportional to the water consumption entering the checks.

$Q=q_{1}+q_{2}+\ldots \ldots+q_{n} \quad\left(\mu^{3} / c, \pi / c\right)$

or

$Q=\sum q\left(м^{3} / c, л / c\right)$

Here: $Q$ is the water consumption of the edge covered with the film;

the flow of water entering the q-check.

The water flow rate for each test should be designed according to the water capacity of the ring grates around the tree seedlings (Figure 4). 


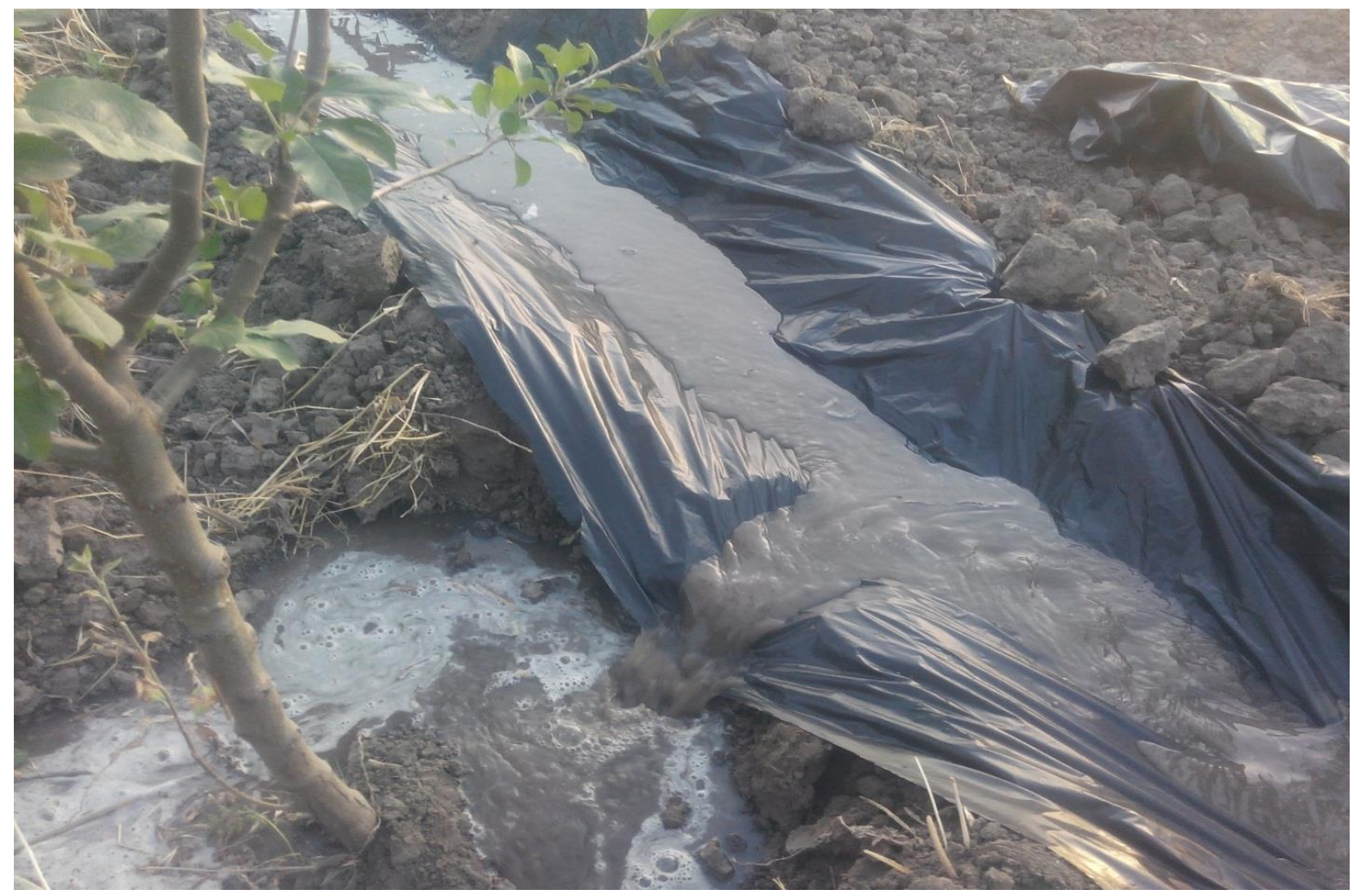

Figure 4. Laying film on irrigation canals when watering gardens

\section{CONCLUSIONS}

This means that the use of drip and sprinkler irrigation methods in apple orchards of Syrdarya White Gold Fiber Garden LLC, where we conduct experiments, is closer to the surface and mineralized than in other areas, which leads to several inconveniences. Therefore, it is enough to slightly improve the traditional methods of ground irrigation in these areas. That is, it is advisable to use flexible portable irrigation pipes or the method of irrigation by covering the edges with film. When watering is organized in this way, it is possible not only to reduce infiltration and evaporation of water but also to regularly monitor the flow of water supplied to the owners. This saves $15-20 \%$ of irrigation water. It is also possible to increase the efficiency of water use by 1.2-1.3 times not only when irrigating industrial crops, but also when irrigating orchards and vineyards.

\section{REFERENCES}

1. Decree of the President of the Republic of Uzbekistan dated February 7, 2017 UP-4947 "On the strategy of actions for the further development of the Republic of Uzbekistan"

2. M.M. Sarimsakov, H.R. Ibragimov. (2018). Osmosis watering of intensive gardens. J. 
Actual problems of modern science, No. 4. Moscow, Sputnik +. pp. 173-179.

3. Yu.D. Javakyants. (2006). Recommendations for soil cultivation in orchards and vineyards of Uzbekistan. Tashkent.

4. Dospeksov B.A. (1985). Field experiment methodology. Moscow. Agropromizdat. $351 \mathrm{p}$.

5. Olgarenko G.V., Gorodnichev V.I. at all. (2015). Resource-saving energy-efficient environmentally friendly technologies and technical means of irrigation: Information. Moscow. Rosinformagrotech. 265 p.

6. Terenko G.N. (2013). Determination of the equivalent moisture capacity of the soil. Scientific works of the State National University. North Caucasian Research Institute of Horticulture and Viticulture. Krasnodar. Vol. 3. 79 p.

7. Adrien van Gelder, Ralph van Gelder, Gerald Gunther. Corneliu Eftodi, edited by Nadirbek Kachkinbaev. (2016). "My profitable farm”. Bishkek. M-Maxima. 311 p. 